\title{
Del sonido corralero al merequetengue: glocalidad, localidad regional y translocalidad musical en la Costa Chica de México*
}

\author{
DOI: https://doi.org/10.18046/recs.i34.4308
}

\begin{abstract}
From the corralero Sound to merequetengue: Musical Glocality, Regional Locality, and Musical Translocality in the Costa Chica of Mexico
\end{abstract}

\section{Carlos Ruiz-Rodríguez ${ }^{* *}$}

Instituto Nacional de Antropología e Historia (Ciudad de México, México)

\footnotetext{
* El presente escrito conforma una línea de investigación que se desprende de un proyecto en torno a las tradiciones musicales afrodescendientes de la Costa Chica de México, auspiciado por el Instituto Nacional de Antropología e Historia (México). Artículo de investigación recibido el 20.09.2020 y aprobado el 03.01.2021.

** Doctor en Antropología y Maestro en Etnomusicología por la Universidad Nacional Autónoma de México (UNAM) (México). Profesor-investigador titular del Instituto Nacional de Antropología e Historia y docente en la Licenciatura en Etnomusicología de la UNAM (México). Ha realizado investigaciones sobre las tradiciones musicales afromexicanas, la organología mexicana, la salvaguardia del patrimonio musical y el desarrollo histórico de la etnomusicología en México. Correo electrónico: ruiroca@hotmail.com ORCID: https://orcid.org/oooo-0oo2-8491-9940
} 


\section{Cómo citar/How to cite}

Ruíz-Rodríguez, Carlos (2021). Del sonido corralero al merequetengue: glocalidad, localidad regional y translocalidad musical en la Costa Chica de México. Revista CS, 34, 265-299. https://doi.org/10.18046/recs.i34.4308 


\section{Resumen}

En los años sesenta del siglo XX, agrupaciones musicales provenientes de la sonoridad corralera de la costa caribeña colombiana hicieron giras en México. Su influencia propició el surgimiento de algunas agrupaciones locales en la franja costeña afrodescendiente del sur de México, llamada Costa Chica. Uno de estos grupos, Mar Azul, colaboró a fraguar el llamado merequetengue, genérico musical que fungió como vehículo identitario y amasijo de una estética propia, dando cuenta de procesos glocales y de una marcada localidad regional. La importancia que adquirió esta agrupación derivó, más tarde, en procesos translocales, al formar parte sustancial de la vida musical de la población costeña migrante, tanto en la Ciudad de México como en varios estados de los EE. UU. El presente escrito analiza estos procesos - que evidencian relaciones Sur-Sur entre poblaciones rurales afrodescendientes-, mediante las nociones de glocalidad, localidad regional y translocalidad musical.

\section{PALABRAS CLAVE:}

afrodescendiente, merequetengue, charanga, glocalidad, translocalidad

Toward the end of the 6os musical groups with origins in the corralero sound from the Colombian Caribbean coast made several tours in Mexico. Their influence led to the emergence of local groups in the Afro-descendant coastal strip of Costa Chica in southern Mexico. One of these groups, Mar Azul, collaborated to forge the so-called merequetengue, a music genre that served as an identity vehicle and a mixture of local aesthetics, evidencing glocal processes and regional locality. Later on, the importance this group acquired led to translocal processes, as it became a substantial part of the musical life of the migrant coastal population, both in Mexico City and in several states of the USA. This paper analyzes these processes -which show South-South relations between Afro-descendant rural populations- making use of the notions of glocality, regional locality, and musical translocality.

\section{KEYWORDS:}

Afro-descendant, Merequetengue, Charanga, Glocality, Translocality 



\section{Introducción}

Desde hace varias décadas, los procesos culturales en las sociedades humanas se han dinamizado de manera más pronunciada que en tiempos precedentes. En lo musical, estos procesos han ofrecido una gama muy diversa de respuestas a nivel local, debido a la compleja manera en que interactúan globalmente los múltiples elementos que conforman a las culturas musicales. En Latinoamérica, pueden observarse interesantes casos de contacto que dan muestra de procesos de glocalización delineados por fuertes localidades regionales, que incluso derivan en translocalidad musical. Uno de ellos es la fuerte influencia de la música popular colombiana en tierras mexicanas durante el último tercio del siglo XX.

Hacia fines de los años sesenta, algunos grupos colombianos de música popular se hicieron presentes mediante giras de conciertos en varias entidades de México. Las actuaciones de estos grupos tropicales llegaron a ocupar un nicho de consumo que venía trazándose desde el declive del danzón y el mambo, y que la industria musical pronto identificó como un prometedor mercado musical (Moreno, 1989). Algunos estudiosos han investigado el legado de estas agrupaciones musicales colombianas en medios urbanos (Blanco, 2003; Olvera, 2000; 2006); sin embargo, todavía poco se sabe de su impacto en localidades rurales, donde las dinámicas de producción, performance, circulación y consumo han seguido sus propios derroteros. Tal es el caso de la Costa Chica, franja costera interétnica localizada entre Acapulco (Guerrero) y Puerto Ángel (Oaxaca), en México, donde surgieron varias agrupaciones musicales a partir de la influencia colombiana. Ejemplo de estos grupos emergentes es el legendario conjunto Mar Azul, el cual, como pretendo argumentar aquí, es un elemento constitutivo de una identidad regional costeña.

El acercamiento pretende advertir el surgimiento de este grupo como proceso de glocalización. Retomo aquí esta noción, elaborada por Robertson (1992)리 para explorar la manera en que el sonido corralero colombiano se adaptó a las prácticas locales de la Costa Chica, dando cuenta de procesos donde "las culturas locales adaptan y redefinen cualquier producto cultural global para ajustarse a sus necesidades, creencias y costumbres particulares" (Haque, 2019:95-96); dicha adaptación supone inscribir "significados locales específicos, efectivamente reinterpretando y localizando objetos, textos e imágenes globales” (Bennett, 2015: 223).

La glocalización del llamado sonido corralero atestigua un lapso previo al surgimiento y efectos de internet, pero donde ya es posible advertir relaciones media-

1. Robertson (1992: 173) señala que la primera formulación del término glocalizar, proveniente de la palabra japonesa dochakuka (traducida como localización global), se relacionaba con temas de mercado, en un momento en que ese país se integraba exitosamente a la economía global. 
das por un comercio musical que se encamina a acelerar la dinámica de contacto entre localidades distantes, de donde derivan nuevas emergencias musicales. No obstante, estas emergencias toman su propio carácter mediante una estética local que se reproduce y mantiene socialmente, colaborando con la construcción de una identidad regional. El concepto de glocalización pone de relieve la interpenetración que existe entre lo global y lo local, aunada al sentido particularizante de lo global, promoviendo tanto homogeneidad como heterogeneidad cultural (Robertson, 1995).

En el marco de este proceso, identifico algunos elementos que, en la opinión local, explican el surgimiento del grupo Mar Azul, así como el consumo y reproducción de su música hasta nuestros días. Sugiero aquí que estos elementos pueden ser entendidos como ejes de construcción identitaria, reflejo de la manera en que localmente se asumen las valoraciones estéticas, la construcción del lugar y los vínculos comunitarios que confieren localidad regional a esta expresión musical (Hutchinson, 2016: 114). Dicha noción alude a aquello que interviene para que un grupo de personas se imaginen unidas por lazos comunes de identidad en vinculación con una delimitación territorial, y que se refuerzan y valoran tácitamente en el consumo y reproducción de esta música. El uso de la noción de localidad en las investigaciones musicales se ha vinculado con la construcción de identidades en escenarios urbanos, aunque poco preocupados por "las relaciones 'orgánicas' entre la música y la historia cultural de lo local" (Bennett; Peterson, 2004: 7). En el caso rural que aquí abordo, atiendo esta consideración y argumento que en este proceso glocal las condiciones históricas ofrecieron un momento coyuntural de actualización y reafirmación identitaria regional que favoreció la emergencia y aceptación de estas agrupaciones.

Por otra parte, el presente ensayo aborda también un proceso posterior a la emergencia y éxito regional de estos grupos musicales costeños, ahondando en cómo el grupo Mar Azul extendió su proyección geográfica más allá de las fronteras mexicanas, favoreciendo un vínculo translocal con las comunidades de costeños migrantes en Estados Unidos. Entiendo por translocalidad el cambio de localidad de prácticas musicales a un territorio distinto al de su origen, el cual conlleva procesos de mediación y recontextualización que suscitan nuevas percepciones y significados en una "comunidad imaginada" (Wong, 2012: 206). En ese sentido, se identifican algunas de las transformaciones de las prácticas musicales, principalmente en su promoción y contextos performativos, a la par de enfatizar en cómo Mar azul y otras agrupaciones costeñas han servido a los migrantes para extender simbólica y transnacionalmente su patria chica, intensificando los lazos de identificación regional en la diáspora a la manera de un "regionalismo transnacional" (Hutchinson, 2006: 65) que distingue su pertenencia costeña. 
Si bien el presente ensayo se enfoca en una expresión musical que podría comprenderse dentro de la ambigua noción de música popular (Middleton; Manuel, 2001), el estudio forma parte de una investigación más amplia en torno a la música tradicional de la Costa Chica apoyada en trabajo de campo realizado en dicha región durante los últimos 20 años. En ese lapso, he visitado más de media centena de comunidades afrodescendientes, realizando entrevistas extensas a una diversidad de personas oriundas de la región. De especial relevancia fue la relación establecida, desde el año 2016, con el acordeonista Esteban Bernal, uno de los dos últimos miembros sobrevivientes de aquel Mar Azul de los años setenta, quien colaboró a dar mayor sustento al contenido de este escrito. Otras fuentes, tanto hemerográficas como discográficas, citadas en las referencias, procuran ampliar la información etnográfica.

Este ensayo pretende contribuir al campo de estudios que exploran relaciones musicales entre espacios rurales del Sur Global, tomando como eje la construcción musical de las identidades sociales y el espacio regional. El caso de Mar Azul muestra la amplia gama de vertientes que pueden tomar estos vínculos globales, especialmente en el nivel de los microuniversos locales, en un momento previo a la aparición del internet y el auge de la industria musical, en pleno inicio de la fase neoliberal del capitalismo global durante los años ochenta (Haque, 2019). Asimismo, apunta a introducirse en la reconstrucción del pasado reciente de estas expresiones, localizadas tanto en su entorno de origen como en sus consecuentes proyecciones en espacios transnacionales.

El ensayo se divide en cuatro partes. En la primera, se ofrecen algunos antecedentes que recuperan cuándo y cómo llegó la influencia del sonido corralero colombiano a México, así como la manera en que este proceso detonó el surgimiento de grupos locales de merequetengue. En la segunda parte, se aborda la emergencia de una de estas agrupaciones, Mar Azul, la cual ejemplifica cómo la cultura local glocalizó expresiones musicales fuereñas ajustándolas a las estéticas locales. Siguiendo esa misma idea, la tercera parte del artículo destaca las condiciones históricas que favorecieron el auge de esta música, ahondando en algunas particularidades de su producción, circulación y consumo que colaboraron a conferirle localidad regional. La última sección muestra de qué manera se conformaron lazos translocales de esta música con comunidades migrantes procedentes de la Costa Chica, tanto en la Ciudad de México como en distintos estados de los EE. UU., y el importante papel identitario que juegan estos vínculos todavía en la actualidad. 


\section{La sonoridad corralera en México y la Costa Chica}

El actual arraigo de la música de ascendencia caribeña colombiana en México surge a partir de una relación musical con precedentes en el segundo tercio del siglo XX. De acuerdo con Blanco (2008), el porro colombiano viaja en los años cuarenta a tierras mexicanas en la voz de Luis Carlos Meyer, importante exponente barranquillero que radicó en México por un tiempo y quien ayudó a socializar el género en el ámbito del espectáculo. El porro adquirió tal importancia que incluso puede encontrarse en varias películas de la llamada época de oro del cine mexicano. Esa numerosa producción cinematográfica se retransmitió asiduamente por la televisión abierta en México durante las siguientes décadas y hasta inicios del presente siglo. Para muchos mexicanos citadinos, ese fue su primer contacto con la producción musical popular de mediados del siglo XX, no solo de México, sino de varias partes de Sudamérica. Allí se daban cita una diversidad de manifestaciones musicales, muchas de ellas rurales, adaptadas o re-inventadas para la audiencia masiva. Entre ellas se encontraba el porro.

Como bien señala Blanco (2008), la exitosa incursión del porro allende sus fronteras tradicionales le convierte en una especie de genérico que engloba a varios tipos de música colombiana de esos años. De alguna manera, la aceptación del porro en el gusto musical mexicano de los años cincuenta colaboró a abrir camino a la cumbia, la cual se internacionalizó unos años después a través de músicos procedentes de la Costa Atlántica colombiana que, en el seno de la efervescente industria disquera del Medellín de esos años, forjaron todo un movimiento de música tropical bailable manufacturado en Antioquia, Colombia (Burgos, 2001).

Un grupo que tuvo un papel muy importante en México fue Los Corraleros de Majagual, agrupación colombiana "que se caracterizó por generar un nuevo sonido a partir de la mezcla de diferentes ritmos de la Costa como la cumbia, el porro y el vallenato" (Blanco, 2005: 21). Durante los años sesenta y setenta, los Corraleros realizaron exitosas giras, tanto en los grandes centros urbanos como en las pequeñas localidades del interior de México. Hay que recordar que la capital de este país seguía jugando un papel muy importante como "ciudad trampolín para el mercado latino" (Blanco, 2008:54), perfil que la convertía en atractivo destino para las nuevas propuestas musicales.

El éxito de Los Corraleros de Majagual -y de la cumbia en general- en México obedeció, entre otros factores, a la expansión de los centros urbanos como Monterrey, Guadalajara, Acapulco, Veracruz y la Ciudad de México, que fueron receptores de una enorme migración rural en los decenios del setenta y ochenta (Instituto Nacional de Estadística y Geografía, 2001). Las temáticas migrantes del repertorio 
corralero y su narrativa de la vida campesina hicieron eco en las clases populares urbanas que se daban cita en un creciente número de bailes colectivos durante los años setenta. En este contexto, Los Corraleros de Majagual dieron amplia proyección internacional a la cumbia, otro genérico que comprende una diversidad de ritmos caribeños colombianos, y que, en el caso mexicano, tuvo amplia repercusión local'2.

$\mathrm{Si}$ bien ahondar en el proceso de surgimiento de Los Corraleros de Majagual rebasa los objetivos del presente escrito, conviene recordar brevemente el contexto histórico en el que afloró esta agrupación. En 1953, tras un golpe de Estado en Colombia, el militar Gustavo Rojas Pinilla toma el poder de dicho país. En los cuatro años que duró su gobierno, de corte nacionalista, Rojas dinamizó la economía y realizó obras de infraestructura, transportación y comunicaciones. Una de ellas se relacionó con la Televisión Nacional de Colombia y "la aparición de una industria discográfica nacional, misma que tuvo como epicentro a la región de Antioquia, conocida desde entonces como la capital industrial de Colombia" (Montoya, 2014: 43). Paralelamente, Rojas impulsó políticas que suspendieron la importación de fonogramas argentinos y mexicanos -que por entonces eran ampliamente consumidos en Colombia-, incentivando así tanto la producción musical como la industria fonográfica colombiana. Montoya (2014) ofrece un recuento de ese proceso develando cómo la constitución de varios sellos discográficos en Medellín tuvo amplias repercusiones en la creación musical local. Es en ese marco que toma auge la costeñización musical del país, en la que jugó un papel fundamental el sello discográfico Discos Fuentes (Hernández, 2015).

De acuerdo con Blanco (2008), el carácter del sonido corralero puede atribuirse a Antonio Fuentes, fundador de Discos Fuentes, quien, avizorando el gusto de los grupos populares y los desplazamientos sociales a las ciudades, crea un sonido cercano a la sensibilidad y estética de estas nuevas colectividades citadinas, clase social emergente que encuentra en la mezcla de música caribeña colombiana con ensambles novedosos (como los combos) una expresión cercana a su sensibilidad estética. Como señala Parra (2017:124), Discos Fuentes, por esos años, sería todo un "laboratorio musical" presto a experimentar con músicos, ensambles y repertorios en pos del éxito comercial. El ensamble instrumental que conjunta un acordeón tradicional con trombones, saxos y clarinetes de orquesta, al lado de congas, timbaletas, cencerro y platillos, es más tarde ampliado con la inserción del bajo eléctrico. Ese

2. En un reciente libro compilado por Parra (2019), pueden encontrarse acercamientos críticos, no esencialistas, en torno a la construcción discursiva de la cumbia, así como algunos ejemplos de su proyección en el ámbito latinoamericano. 
ensamble, mezclado con elementos tradicionales del humor, la espontaneidad y las temáticas campesinas, conforma la base del éxito del sonido corralero.

En el espacio latinoamericano, el productor colombiano Antonio Fuentes no solo "crea una sonoridad a la medida de (...) nuevos grupos sociales citadinos" (Blanco, 2008: 41), sino que toma conciencia de ese incipiente mundo como un solo lugar, más conectado por el creciente desarrollo tecnológico. Siguiendo a Haque (2019), uno de los aspectos que puede caracterizar a la globalización es precisamente una conciencia subjetiva del mundo como un todo, en conjunción con una conectividad social y cultural. La cumbia, de ascendencia colombiana, trasciende el espacio regional y alcanza dimensiones nacionales para, poco después, proyectarse ante audiencias internacionales, adquiriendo un cariz global al exportarse mediante giras, soportes fonográficos y vías mediáticas, creciendo significativamente en el marco de una industria musical.

El paso de Los Corraleros de Majagual por México tuvo repercusiones profundas en este país, que incluso se reflejan en la producción del grupo con piezas como "Charanga en México", que dan cuenta de esa relación musical3. Un caso notable es el de la ciudad de Monterrey, donde existe actualmente todo un movimiento musical en torno a la llamada música colombiana, el cual, según Blanco (2005:30), arraigó debido a la prolongada estancia de Los Corraleros de Majagual en esa urbe por los años sesenta. Empero, la influencia de esta agrupación trascendió la esfera del noreste mexicano y detonó diferentes procesos en otras zonas del país durante la misma época. La visita de los Corraleros a importantes polos regionales de la Costa Chica, como Acapulco o San Marcos, dejaría una huella profunda en el gusto regional: de acuerdo con el acordeonista Esteban Bernal (comunicación personal, 09.09.2016), los Corraleros hicieron una gira de conciertos por la Costa Chica a mediados de los años sesenta, itinerancia que convirtió a este grupo en la figura más importante del nomadismo cumbiero colombiano, siendo el más escuchado en la región ${ }^{4}$.

De manera similar a lo que pasó en Monterrey, el acordeonista Alfredo Gutiérrez y Los Corraleros de Majagual fueron un referente central para toda una generación de músicos y oyentes; sin embargo, a diferencia de Monterrey, donde los acetatos se vendían en tiendas y la música era reproducida en bailes callejeros por sonideros (Olvera, 2006: 32), en la Costa Chica los discos se compraban directamente en las

3. La pieza se incluye en el fonograma Ésta sí es salsa, publicado por Discos Fuentes (MFS-3103) en 1970. También puede escucharse en línea en https://www.youtube.com/watch?v=XeRiRR_bBuk

4. Otro factor que contribuyó fue la estadía del acordeonista colombiano Aniceto Molina, en un grupo costeño contemporáneo al Mar Azul y de gran arraigo local, La Luz Roja (de San Marcos, Guerrero), quienes lo contrataron para tocar con ellos a mediados de los años setenta (Esteban Bernal, comunicación personal, 27.07.2018). 
presentaciones de los Corraleros (o eran encargados a parientes de la Ciudad de México) y se reproducían en los altavoces comunitarios encargados de difundir los anuncios locales (Esteban Bernal, comunicación personal, o9.09.2016).

Al final, los fonogramas de los Corraleros circularon en las costas de Guerrero y Oaxaca, pero, a diferencia de la influencia que ejercieron en Monterrey, centrada en la periferia marginal de la urbe, el impacto del nomadismo cumbiero en la Costa Chica hizo mella abierta y generalizada en la cultura, escapando a instituirse como un movimiento subterráneo. La sonoridad corralera se adoptó y adaptó a una versión regional costeña -que encuentra también lazos con un boom en ascenso de la llamada música tropical a nivel nacionals-, resultando en la emergencia musical de lo que hoy se conoce en la Costa Chica como merequetengue, charanga o guaracha ${ }^{6}$. Se trata de música con fuerte influencia de la costa atlántica colombiana, basada en repertorios diversos (paseos, cumbiones, marieles, entre otros), aunque de clara reformulación local.

Desde entonces, el llamado merequetengue tomó carta de identidad costeña, integrándose como componente fundamental de la cultura de esta región. El eventual surgimiento del grupo Mar Azul, que llega a convertirse en uno de los más representativos de la Costa Chica, es muestra de ello. La emergencia de esta y otras agrupaciones da cuenta de un proceso de glocalización (Robertson, 1995), donde una expresión musical procedente de otras latitudes se moldea de acuerdo con las preferencias locales. Conviene entonces abordar este proceso para indagar con mayor detalle cómo es que surge Mar Azul y cómo este grupo adopta y adapta el sonido corralero ayudando a configurar una música identificada como propia de la Costa Chica.

\section{Música arrecha, música glocal}

De acuerdo con el testimonio de José Antonio Tornez (Alvarado, 2012), el grupo Mar Azul fue fundado en 1974 en la comunidad de Chacahua (Oaxaca), por iniciativa de él mismo, quien invitó a Bertín Gómez (voz y guitarra), Margarito Larrea (güiro),

\footnotetext{
5. La internacionalización de la cumbia en México daría pie a versiones mexicanas ampliamente comercializadas, como la música de Mike Laure en los años sesenta, y la de Rigo Tovar y su Costa Azul, en los setenta. En su momento, la categoría música tropical fue bastante común en el medio empresarial discográfico para identificar una gran cantidad de expresiones como el danzón, el mambo, la rumba y el chachachá, entre otras (Geijerstam, 1976).

6. En la Costa Chica, el término merequetengue no suele tener otro uso o significación fuera del musical, aunque, como en otras partes de México, se utiliza ocasionalmente en el lenguaje cotidiano como sinónimo de relajo, desorden, barullo, falta de seriedad y desmán.
} 
Abraham Bernal (tarolas) y Jesús Hernández (voz) a formar la agrupación7. Según José Antonio Tornez, fue su tío, Jesús Tornez, quien sugirió el nombre para el grupo y con el que se hizo famosa la agrupación. En la opinión de Esteban Bernal (comunicación personal, 09.09.2016), el nombre dado a la agrupación no pudo ser más pertinente, pues alude a la procedencia diversa de sus integrantes oriundos tanto de la Costa Chica como de la contigua región de la Costa Grande: Tornez, de San Luis de la Loma (Guerrero); Gómez, de Arcelia (Guerrero); Larrea, de Río Grande (Oaxaca); Bernal, de Corralero (Oaxaca); y Hernández, de Los Pocitos, cercano a Chacahua (Oaxaca).

En sus inicios, el ensamble instrumental de Mar Azul se conformaba por bajo eléctrico, requinto (guitarra eléctrica), güiro, tarolas (pailas/timbaletas) y dos voces. A partir del segundo LP, se integra el acordeón de teclas de Misael Lázaro (procedente de Ayuquezco, Oaxaca) y la tumba (conga) de Fernando Pedro. Al menos durante los tres primeros discos LP se conservan estos integrantes en la agrupación. No es fácil saber si Margarito Larrea formó parte de la agrupación en el cuarto y quinto discos de Mar Azul; sin embargo, alrededor de 1976, luego de un accidente automovilístico del grupo-donde uno de sus integrantes quedó paralítico-, hubo varios desacuerdos y al menos la mitad de sus miembros abandonaron la agrupación.

Para el sexto disco, una nueva alineación compone a Mar Azul: se integran Esteban Bernal (acordeón) y José Luis Lozano (requinto), al lado de los elementos originales Jesús Hernández, José Tornez y Fernando Pedro. Con Esteban Bernal (oriundo de San Nicolás, Guerrero), Mar Azul no solo gana un talentoso acordeonista, sino un creativo compositor que contribuirá a consolidar el sonido característico de esta agrupación a fines de los setenta y la década de los ochenta.

En sus inicios, Mar Azul se presenta por toda la Costa Chica, así como en las regiones colindantes de la Costa Grande (de Acapulco, Guerrero a la ciudad Lázaro Cárdenas, Michoacán) y varias localidades del Golfo de México. En no pocas ocasiones alternaron con grupos exitosos a nivel mediático como Acapulco Tropical o Rigo Tovar y su Costa Azul. El éxito de Mar Azul y otras agrupaciones de merequetengue surgidas en los años setenta (Acapulco Tropical, La Luz Roja y Corralero Navy, Apache 16) propició la emergencia regional de una gran cantidad de grupos

7. La fundación del grupo se volvió un tema polémico y objeto de pugna legal años después. Aquilino Hernández, actual director y heredero del legendario Mar Azul de su desaparecido padre, Jesús Hernández, señala que la fundación del grupo fue en 1973 (Méndez, 2016). Si bien varios de los integrantes originales se atribuyeron el origen y nombre de la agrupación, lo cierto es que en el grupo fueron tomando más importancia quienes estaban a cargo del canto: Jesús Hernández y Bertín Gómez, pues eran la imagen principal ante el público, además de ser quienes compusieron el mayor número de piezas durante los primeros cinco discos LP. No obstante, la fama que adquirió el grupo a través de los años se debió a una diversidad de composiciones de distintos integrantes que lo conformaron en su historia. 
locales durante los años ochenta, en pleno auge de la llamada música grupera (Olvera, 2006) ${ }^{8}$. Al paso del tiempo, algunos de los exintegrantes del grupo intentaron tener éxito conformando nuevas agrupaciones que, durante la década de los ochenta, tomaron el nombre de Mar Azul: El Internacional Mar Azul, El Original Conjunto Tropical Mar Azul, entre otros ${ }^{9}$. Prácticamente, Mar Azul fue un semillero de grupos que, de una u otra forma, encontraron sus propias audiencias y canales de difusión. Actualmente, varias agrupaciones con variantes del nombre Mar Azul permanecen vigentes, dirigidas por los parientes cercanos de sus fundadores o bien por exintegrantes de los grupos derivados del primero.

Una cuestión que destaca de la historia de Mar Azul es su enorme éxito regional, lo cual vuelve de interés tratar de identificar qué factores favorecieron la amplia aceptación de esta agrupación. De acuerdo con la valoración que ofrecen los testimonios recogidos localmente, una de las causas más importantes fue la capacidad de Mar Azul para crear una expresión profundamente regional. Al indagar sobre qué le otorgaba identidad local a esta música, al menos tres parámetros emergieron para identificar a este estilo como propiamente costeño: las temáticas literarias de sus piezas, el sonido del ensamble instrumental y el llamado estilo musical arrecho. Aunadas a estos elementos, también fueron mencionadas la familiaridad de los contextos performativos para el público y la proximidad de los músicos con la audiencia ${ }^{10}$.

A diferencia de lo que sucedió con la influencia colombiana en otros lugares de México, en la Costa Chica los músicos prácticamente no grabaron temas procedentes de aquel país, pues desde épocas tempranas comenzó a componerse localmente ${ }^{11}$. En ese sentido, un factor determinante del éxito y aceptación regional de Mar Azul fue la originalidad de sus composiciones, reflejada en las letras de su repertorio. Esta agrupación retomó las temáticas campesinas del sonido corralero colombiano, pero las adaptó idiosincráticamente refiriendo a las costumbres y vida cotidiana de la Costa Chica.

8. Mar Azul, por ejemplo, tuvo un enorme éxito entre 1974 y 1982, período en el que publicaron alrededor de 17 discos LP.

9. El 26 de julio de 2002 presencié por primera vez un concierto de El Internacional Mar Azul en la comunidad de San Nicolás (Guerrero); para entonces, había ya al menos 4 Mares Azules en la región. Actualmente, los conjuntos que llevan ese nombre rebasan la docena de agrupaciones y más de media centena de producciones discográficas.

10. Estos dos factores serán abordados en la sección subsecuente, al lado de otros elementos que contribuyeron a conferirle localidad regional a esta música.

11. Después de ese primer contacto, del que deriva el merequetengue, el consumo local de música colombiana se limitó a seguir la trayectoria de un puñado de grupos como los de Alfredo Gutiérrez o Aniceto Molina, de quienes se siguen vendiendo producciones a nivel regional. 
La primera producción discográfica de Mar Azul (Figuras 1 y 2) estableció el sonido característico que identificará después a la llamada música de merequetengue o charanga. Destacan, en primera instancia, los nombres de algunas de las piezas, todas ligadas a la región, como son: "Pinotepa Nacional", "Mi Chacahua", "La vida del pescador" " "Fiesta en Chacahua". La lírica de cada una de estas piezas dibuja, en su simplicidad, estampas cotidianas con las que los oriundos de la región rápidamente se identificaron. Los siguientes fonogramas reafirmaron esa tendencia con piezas como "Yo tengo una morena", "El burro viudo" y "Lo que le pasó a Alfredo", entre otras. Algunas estrofas de estas piezas, hoy consideradas ya clásicas de la agrupación, ilustran este aspecto. "Pinotepa Nacional", por ejemplo, alude al espacio regional en relación con la identidad costeña:

Soy costeño de nación, me gusta bailar la cumbia, y alegre de corazón, no me ganará ninguno ${ }^{12}$.

FIGURA 1 Carátula del LP Conjunto Mar Azul (ca. 1974)

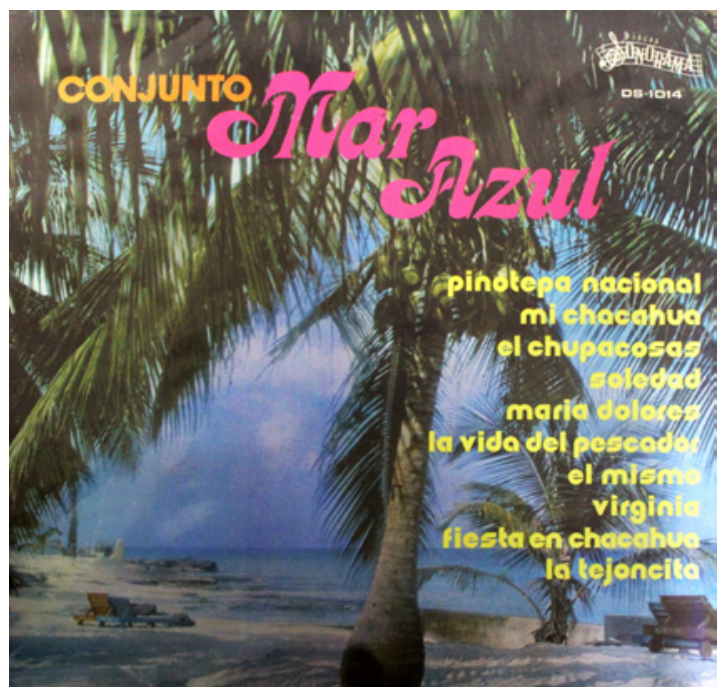

Fuente: Acervo fonográfico de la Subdirección de Fonoteca, INAH.

12. Estrofa de la pieza "Pinotepa Nacional”, de la autoría de Jesús Hernández, procedente del fonograma Conjunto Mar Azul (ca. 1974). México: Sonorama. 
FIGURA 2 Contraportada del LP Conjunto Mar Azul (ca. 1974)

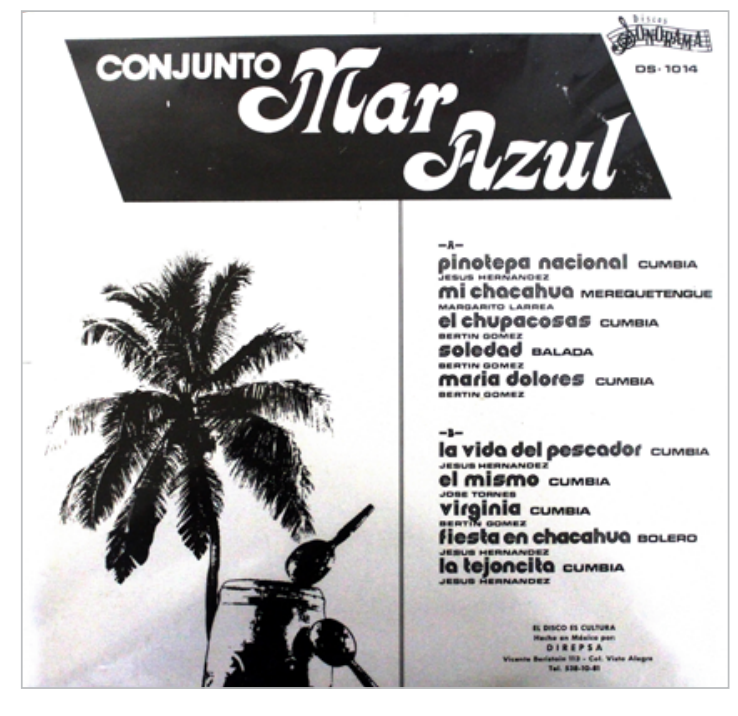

Fuente: Acervo fonográfico de la Subdirección de Fonoteca, INAH.

Otro ejemplo es "Mi Chacahua", pieza que hace referencia a una zona al sur de la Costa Chica que, por su rica flora y fauna, fue la primera área protegida por el Gobierno mexicano como Parque Nacional (Lagunas de Chacahua). El sitio es motivo de orgullo para todo costeño, a la par de ser el lugar donde Mar Azul se formó:

Muy bonito mi Chacahua, nadie lo puede negar, porque tiene sus palmeras en la orillita del mar, por eso yo no me voy de allí porque es mi tierra donde nací.

\section{(...)}

Tiene palmeras inquietas

de belleza tropical y también tiene su faro en la orillita del mar, 
por eso yo no me voy de allí

porque es mi tierra donde naci'is.

De acuerdo con los testimonios locales, uno de los aspectos más entrañables de esta música es su cercanía con la vida cotidiana costeña. Entre las actividades productivas de la Costa Chica, la pesca es una de las que tiene mayor arraigo, y es retratada por una de las cumbias de Jesús Hernández:

\section{La vida del pescador \\ es una vida muy sana, comienza con el domingo, \\ los seis días de la semana. \\ Unos se van a la pesca, otros se quedan tomando, esperando al compañero, para seguir parrandeando ${ }^{14}$.}

Poco después, las composiciones de Esteban Bernal reafirman ese habitual humor costeño que oscila entre la ingenuidad descriptiva del medio natural y el verso metafórico de doble sentido; piezas como "El cucuniño", "El escorpioncillo", "El cuinique”, "Pescando camarón”, “El caballo sabanero", “El molito de armadillo", "El hombre pachanguero" o "El vainón" son ejemplo de ello. Puede afirmarse que Bernal fue un agente central en la consolidación de este estilo costeño, como explica él mismo:

hombre, cómo le gustó a la gente eso, ¿eh? Todas las historias, la gente les pone atención, sí, y yo casi, cuando yo empecé a ser músico, luego pensé, digo: "Bertín Gómez compone: que te quiero, que te adoro", que todo eso, puro "que te quiero", yo voy a buscar la forma de componerle a los animalitos, digo, empecé con ese mole de armadillo, que "El cucuniño" (...) "El escorpioncillo", "Los bueyes de don José Molina” (...) tengo muchas, "El pájaro de San Antonio", puras cosas de animalitos, y le ha ido pegando. (...) No, hombre, viera cómo salen de alegres las canciones, ¿eh?, alegres, les pongo alegría, y la gente cómo las baila. (Esteban Bernal, comunicación personal, 09.09.2016)

13. Estrofa de la pieza "Mi Chacahua", de la autoría de Margarito Larrea, procedente del fonograma Conjunto Mar Azul (ca. 1974). México: Sonorama. Puede escucharse en https://www.youtube.com/ watch?v=UZcTuvYkV-c

14. Estrofa de la pieza "La vida del pescador", de la autoría de Jesús Hernández, procedente del fonograma Conjunto Mar Azul (ca. 1974). México: Sonorama. Puede escucharse en https://www.youtube.com/ watch?v=NJW1Ba4TSdM\&t=98s 
Una vez que fui a mi tierra

me invitaron mis amigos:

"Bernal, vamos a mi casa, tengo mole de armadillo..."

Dijeron mis compañeros:

"Eso a mí no me ha gustado...".

Después cuando se los dieron, se lo comían sancochado...15

El mismo Esteban Bernal considera que un factor central en la amplia aceptación regional de sus piezas han sido sus letras hilarantes:

es lo que le gusta a la gente, los chistes, por eso (...) la gente siempre me tiene en la mente, por los chistes... las canciones no tienen tanto de amor, sino que, dije: si yo no hago de amor, tengo que hacer de chiste para que la gente se ría. (Esteban Bernal, comunicación personal, 27.07.2018)

En efecto, la lírica de sus canciones juega con temáticas que son marcadores de identidad procedentes de la vida cotidiana en la Costa Chica: la conducta de la fauna regional, la comida tradicional, las condiciones de vida, la admiración y apego a la propia tierra, entre otros.

De acuerdo con algunas valoraciones locales, un importante rasgo musical que confiere identidad costeña a esta música tiene que ver con el ensamble instrumental. Al respecto, Esteban Bernal afirma que el referente inicial fue la música de Los Corraleros de Majagual y el grupo posterior que conformó su acordeonista Alfredo Gutiérrez, al igual que la influencia de otro destacado acordeonista, Aniceto Moli$\mathrm{na}^{16}$. En su momento, tanto Gutiérrez como Molina fueron clave para caracterizar el sonido corralero colombiano incorporando el acordeón de botones a la orquesta de aerófonos metal/madera. Sin embargo, la adaptación musical de Mar Azul implicó modificaciones en este renglón.

15. Estrofa de la pieza "El molito de armadillo", de la autoría de Esteban Bernal, contenida en el fonograma 16 las nuevasy viejitas consentidas. El Internacional Mar Azul (s.f.). México: Puma Records. Puede escucharse en https://www.youtube.com/watch?v=AawyXgxr4zc. El término sancochado es un localismo del español hablado en la Costa Chica que refiere a un alimento que no está terminado de cocinar, apenas a medio hacer, "entre cocido y crudo" (Efrén Noyola, comunicación personal, 27.07.2018).

16. Bernal incluso caracteriza su propia música como muy similar a la de Aniceto Molina: "Es el mismo ritmo de Mar Azul” (Esteban Bernal, comunicación personal, 09.09.2016). 
Como ya señalaba, en el primer fonograma de esta agrupación el ensamble instrumental se componía de requinto (guitarra eléctrica), bajo (eléctrico), güiro y tarolas, acompañando a dos voces. En este formato, la guitarra eléctrica (sin distorsión o efectos) se encargaba de hacer figuras melódicas y solos. La integración de guitarra y bajo eléctricos se debe, principalmente, a la influencia de Mike Laure y Rigo Tovar, que de alguna forma le restaban aire de orquesta al ensamble tradicional y le otorgaban modernidad ${ }^{17}$. A partir del segundo LP de Mar Azul, se integra el acordeón de teclas como instrumento líder y la guitarra toma un rol secundario. Más tarde, el uso de acordeón de botones presentará claro vínculo con su homólogo colombia$\mathrm{no}^{18}$, al grado de ser adaptado a las estéticas tímbricas de ese país, pues se adecúa alterando las lengüetas de vibración para conseguir timbres roncos (graves), propios en la ejecución de cumbias y merequetengues, o bien timbres sequecitos (agudos) para interpretar corridos (Esteban Bernal, comunicación personal, 09.09.2016).

A pesar de la adopción del acordeón de botones, el ensamble instrumental de Mar Azul no reprodujo el típico combo de doce músicos del sonido corralero, sino que lo redujo a seis elementos, eliminando los aerófonos de metal y lengüetas. Este aspecto es muy importante, pues gran parte del discurso melódico en el repertorio corralero colombiano se basa en el juego constante del acordeón con el trombón $u$ otro aerófono de metal. Por otra parte, en la agrupación nunca se incorporó batería ni teclados eléctricos o sintetizadores, pues, como señala Esteban Bernal (comunicación personal, 27.07.2018), la integración de batería y órgano o piano eléctrico, así como el excesivo uso de letras románticas convertiría a la agrupación en grupo tropical y no de charanga/merequetengue. Así, a diferencia del sonido desarrollado por Rigo Tovar, Mar Azul optó por un ensamble tradicional más apegado a la instrumentación colombiana, aunque resumido en un menor número de instrumentos y con el acordeón de botones como eje rector de la música.

A la par del característico sonido del ensamble instrumental, se encuentra el estilo musical. Mar Azul colaboró a fraguar una mixtura de sonido a la cual se le califica, en la Costa Chica, como música arrecha o arrechera (Figura 3), una categoría utilizada localmente para expresar brío sexual (erección del miembro viril) y que, en este caso, refiere a música alegre, caliente, animada, que invita al goce y el

17. Tanto Laure como Tovar fueron fanáticos del rock. A ambos se les atribuye haber insertado instrumentaciones y timbres del rock a la música atlántica colombiana tocada en México (Blanco, 2008).

18. Piezas clásicas colombianas fundamentadas en el sonido del acordeón de botones, como "La cumbia sampuesana” y "La pollera colorá”, impactaron enormemente en la costa. 
baile $^{19}$. Básicamente, esta música simplificó la polirritmia del sonido corralero y su fuerte basamento en la sección percusiva, subiendo un poco el tempo de las cumbias, basadas en frases melódicas breves y estructuras simples sin improvisación, con ocasionales extrapolaciones del tema melódico de parte del requinto. Aun así, conservaron el ocasional uso de canto responsorial (call and response) entre solista y coro que aparece con frecuencia en el sonido corralero.

Pero quizá el rasgo más interesante sea el manejo del bajo eléctrico que acuñó José Tornez, que suele salir del canon de la figura rítmica de la cumbia (de una negra y dos corcheas), para sustituirla por un bajo con mayor movimiento melódico como base lírica del acompañamiento armónico. En los comienzos de Mar Azul, la figura del bajo fue parte fundamental de cada pieza; como el propio José Tornez señaló en su momento, él inventó un estilo de bajeo que luego copiaron muchos grupos costeños, otorgándole parte de su identidad al merequetengue (Alvarado, 2012). Cabe destacar que, con excepción de Jesús Hernández, quien tenía algunos conocimientos de lectoescritura musical y tocaba la trompeta, los demás integrantes del Mar Azul de los años setenta y ochenta fueron músicos líricos que aprendieron de manera autodidacta.

\section{FIGURA 3 Portada de la compilación de éxitos Lo más arrecho del Conjunto $\operatorname{Mar}$ Azul (2007)}

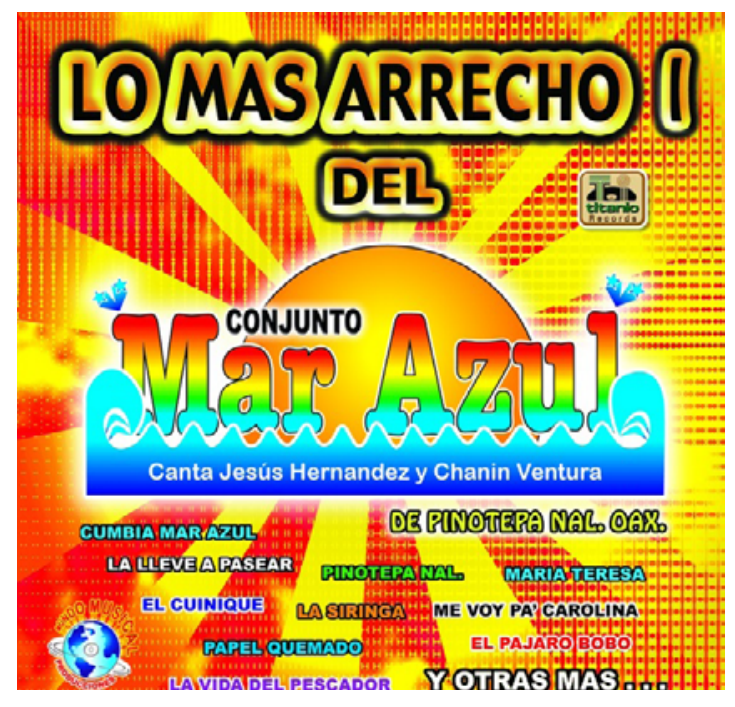

Fuente: Apple Music.

19. Algunos músicos locales todavía diferencian vertientes genéricas como el paseo, el mariel, el merengue o la guaracha, no obstante, el repertorio tiende a generalizarse, ya sea como cumbias o boleros (piezas a tempo lento). 
Si bien este proceso de glocalización musical puede ayudar a explicar la amplia aceptación regional de Mar Azul, el mismo supone cuestiones de orden sociocultural y del propio contexto histórico. El siguiente apartado se acerca a algunos de estos aspectos que favorecieron el auge de esta música a fines del siglo XX.

\section{Música y localidad regional}

El surgimiento de Mar Azul y otros conjuntos de merequetengue ocurrió en condiciones históricas que es necesario tener presentes, pues estas ofrecieron un momento coyuntural de actualización y reafirmación identitaria regional. Para los años setenta del siglo XX, las añejas formas tradicionales de celebración colectiva, como los fandangos de artesa, habían caído ya en el olvido en la Costa Chica (Ruiz, 2013). La desaparición de estos festejos dejó un vacío que fue ocupado por nuevas formas culturales en el marco de una creciente presencia de la radio y la televisión. Lo que se conservaba de la cultura tradicional por esos años para acompañar los festejos eran las pequeñas bandas de instrumentos de metal que ejecutaban repertorios de sones, cumbias, danzones y pasodobles en las celebraciones del ciclo de vida y el calendario festivo comunitario.

Si bien todavía era un tiempo en el que tanto las condiciones como los grupos de población eran más estables que hoy-favoreciendo identidades un tanto más homogéneas donde la noción de comunidad musical tenía mayor sentido-, también era un momento en el que comenzaba a acelerarse el cambio cultural y el desarrollo tecnológico que exponía a estas sociedades a más expresiones musicales llegadas de fuera de la región. Estas condiciones explican parcialmente cómo la influencia musical colombiana detonó el surgimiento de expresiones nuevas que redefinieron los valores musicales regionales en un período tan corto durante el último tercio del siglo XX. El paulatino mejoramiento de la carretera costera, que fomentó una comunicación intrarregional más ágil para los grupos, y la popularización de los aparatos reproductores de fonogramas (LP), que favorecieron la socialización de su música, fueron también otros factores que apuntalaron el auge de las agrupaciones de merequetengue en la región.

De alguna forma, la emergencia de los conjuntos representa un momento de transición que expande el espectro del gusto y consumo de la música tradicional hacia la música popular, pero que ocupa un espacio liminal en la intersección de estas ambiguas nociones. Hasta cierto punto, el surgimiento de estas agrupaciones fue una manera de actualizar la cultura expresiva y el formato festivo de las celebraciones colectivas mediante nuevas temáticas literarias, la ampliación del repertorio y la integración de nuevas tímbricas (con instrumentos electrófonos), así como la posi- 
bilidad de permitir una mayor concentración de personas gracias a los sistemas de amplificación en los bailes comunitarios. No obstante, esta actualización se ciñó al marco de una arraigada localidad regional, producto del largo aislamiento histórico de la región, donde la relación con la música tomaba "la forma de una exploración en curso de uno o más idiomas musicales que se dicen enraizados en un legado histórico geográficamente específico" (Straw, 1991: 373). La práctica musical, con su capacidad de suscitar experiencias intensas, apuntaló sentimientos que fomentaron el imaginario de una identidad regional con características particulares.

La música de Mar Azul no fue grabada por la industria disquera con canales de distribución nacional o internacional, sino por pequeñas casas editoras en las que un empresario independiente invertía para la producción del fonograma. Es posible que la acentuada localidad de estos grupos explique por qué no fueron foco de interés para casas disqueras de largo alcance. La falta de reconocimiento de la gran industria musical del centro del país marca una similitud, pero también una significativa diferencia, con respecto al otro caso de música de influencia colombiana en México: el de la ciudad de Monterrey (Nuevo León).

Olvera (2005:25) señala que, si bien los grupos regiomontanos de música tropical no fueron promovidos por las grandes disqueras del centro de México, la propia infraestructura disquera e industria musical del eje Houston-Monterrey (atendiendo a la demanda musical migrante) permitió el florecimiento de estas agrupaciones, lo cual establece una diferencia importante entre las músicas populares que emergen en el ámbito urbano y las que surgen en el rural. A diferencia de lo que sucedió con el caso regiomontano, donde a la postre la música tropical local se proyectó mediáticamente a nivel global, la ausencia de una industria musical en la Costa Chica favoreció que la producción, circulación y consumo del merequetenge se ciñera -hasta entrados los años noventa-a su región de procedencia. Raras veces los grupos locales consiguieron aparecer en los programas de televisión de transmisión nacional, aunque otros exponentes de la música tropical consolidaron ese gusto musical en el gran público (Olvera, 2005).

En sus inicios, la grabación de los fonogramas de Mar Azul implicó largas sesiones: llegaban a grabar hasta veinte temas en una misma sesión, debido a la escasez de recursos y la pretensión de aprovechar al máximo el alquiler del estudio (Esteban Bernal, comunicación personal, 27.07.2018). Esto obedecía a los costos que tenía que asumir el productor, pues además tenía que llevar a los músicos hasta la Ciudad de México y encargarse de su estadía para realizar las grabaciones. La austeridad de inversión también se reflejaba en la limitada producción de fonogramas: se hacían tirajes de copias en pequeñas cantidades y su distribución casi se limitaba al circuito regional de comercio de discos, tanto en pequeños establecimientos de las 
poblaciones más grandes como en los propios conciertos que ofrecían los grupos en la región. Es importante notar que buena parte de la difusión de esta música se efectuó mediante la circulación de los materiales fonográficos de persona a persona, por el préstamo de discos entre parientes y amigos; los discos no solo eran difíciles de conseguir, sino que prácticamente no se reeditaban. Esto propició que se consolidara un mercado regional de piratería; primero, con el comercio de cintas magnetofónicas (casetes) y, más tarde, con el de discos compactos.

Aunque los fonogramas jugaron un papel importante ayudando a difundir la música de estos grupos, la permanencia de las agrupaciones de merequetengue prácticamente dependió de las presentaciones en vivo ${ }^{20}$. La emergencia de estos grupos y el gusto por su música fue propiciando circuitos musicales de carácter regional, con características que los alejaban de una lógica industrial de consumo. Un aspecto particular era el espacio de las presentaciones. Si bien hoy los espacios de performance también se ubican en el ámbito urbano, en las últimas décadas del siglo $\mathrm{XX}$ la mayoría de las presentaciones de estos grupos se realizaban en el medio rural.

Usualmente, en este entorno, los espacios para los bailes de charanga no eran auditorios o salas de concierto estables y fijas, con escenario y butacas, sino espacios de uso comunal adaptados como recintos temporales de baile. Las plazas centrales de los pueblos o las canchas de baloncesto al aire libre tomaban la función de salones de baile, tan solo separados del espacio público callejero por una improvisada malla de alambre. Templetes elevados a poco más de un metro del piso servían como escenarios, cobijados por estructuras portátiles de austeros juegos de luces y sistemas de amplificación de sonido de variada calidad. Una centena de sillas de plástico rodeaba el espacio del baile, con mesas esporádicas aquí y allá, así como un local improvisado donde se vendían bebidas alcohólicas. Esta forma de apropiación del espacio sigue vigente hasta hoy: la familiaridad del sitio de baile y el hecho mismo de que la música llegue hasta los espacios colectivos de la comunidad ha favorecido también al fuerte arraigo de esta música en la región. La asociación de la experiencia musical con el espacio cotidiano -transformado momentáneamente en lugar de festejo-forma parte del bagaje cultural tradicional generalizado en el entorno costeño.

El patrocinio es también otra particularidad en los eventos de merequetengue. Una de las modalidades más frecuentes sigue siendo la llamada renta de plaza durante alguna fiesta religiosa o del calendario celebratorio comunitario. En esta modalidad, alguna empresa cervecera paga el derecho de exclusividad para venta de cerveza durante la fiesta, con una significativa suma entregada a la comisaría municipal. Ese recurso, generalmente, es utilizado en obras de beneficio comuni- 
tario, como el mejoramiento de la plaza central, la clínica comunitaria, los recintos escolares, la pavimentación de calles o el alumbrado público, etc. Otra modalidad de patrocinio de los bailes es la que auspician los llamados comités o juntas, que son agrupaciones de personas de la comunidad que se comprometen a participar en la organización de festividades religiosas generalmente para pagar promesas a deidades. Una más son las mayordomías tradicionales que comparten entre varias personas, aunque esta modalidad ha venido cayendo en desuso por los altos costos que recaen casi exclusivamente en los mayordomos. Estas formas de patrocinio y organización son características de las festividades tradicionales en el medio rural costeño y se reproducen también para dar cabida a esta música popular.

La forma de publicitar los bailes tiene también sus particularidades. Tradicionalmente, los medios usuales para difundir los conciertos-bailes han sido los anuncios pintados en muros o fachadas a lo largo de la carretera costera; debido a su amplio alcance, el arribo de personas de toda la región conforma una audiencia de clara procedencia regional (Figura 4). De hecho, la convocatoria abierta a todo costeño ha contribuido a que los bailes de merequetengue desdibujen momentáneamente

FIGURA 4 $\quad$ Cartel de baile en Bajos de Coyula (México)

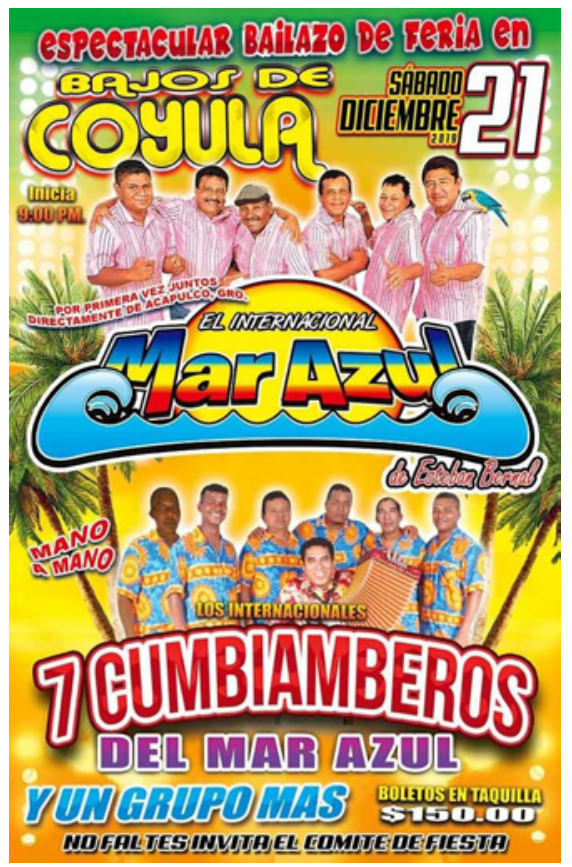

Fuente: Espectacular bailazo (2019). 
algunas diferencias de clase y raza presentes en esta región pluricultural y multiétnica. Una segunda manera de publicitar los bailes, pero más localizada en el nivel comunitario, es en el interior de las poblaciones mediante la llamada bocina. En casi todas las comunidades costeñas existen altoparlantes situados en lo alto de algunas casas, esparcidos en puntos estratégicos de la población. A lo largo del día, los dueños de estas bocinas emiten una diversidad de anuncios por los que obtienen una retribución económica. Los anuncios pueden difundir una diversidad de mensajes: la venta de algún producto o alimento por parte de un particular, avisar a una persona que se le espera en un punto específico o, bien, enviar un mensaje a la población, ya sea de índole religioso, civil o político.

Por otra parte, la vigencia del repertorio de Mar Azul en el consumo musical actual de la Costa Chica es otro tema interesante. Si bien la mayoría de los éxitos musicales de la agrupación es de los años setenta y ochenta, todavía hoy es difícil asistir a una fiesta particular o celebración comunitaria en la que no se escuchen una y otra vez sus temas clásicos. El repertorio de Mar Azul-y en general del merequetengue- ha sido la música de baile por excelencia incluso con el paso de las generaciones. De acuerdo con los testimonios locales, un hecho que explica su vigencia es que se trata de una música hecha por costeños para los propios costeños. El repertorio más gustado tiende a cohesionar una estética compartida que ofrece un particular sentido del lugar, incluso al grado de borrar momentáneamente las diferencias de etnia, clase y raza en los bailes donde se interactúa simplemente entre costeños. En ese mismo sentido, la costa a la que se alude en las piezas no remite a un territorio idealizado, sino a un espacio geográfico cercano y cotidiano de costumbres, lugares o personas familiares a la mayoría de los costeños, que refuerza los lazos de los oyentes con esta región. Básicamente, el repertorio clásico de Mar Azul pondera valores culturales regionales que proyectan imágenes consideradas como auténticas en el imaginario costeño.

Otro aspecto que interviene en la amplia aceptación regional de la agrupación ha sido la cercanía de los músicos con su audiencia. Tanto los músicos que conformaron el primer Mar Azul como los actuales integrantes de alguna de las agrupaciones que hoy portan ese nombre han permanecido, luego del éxito, radicando en sus comunidades, lo cual los ha mantenido cerca de su público de manera cotidiana, sin hacer de ellos figuras públicas en los términos de la industria musical ${ }^{21}$. En mis visitas a la región fue muy frecuente escuchar que las personas hablaran de manera familiar sobre los integrantes del grupo: "Esteban es mi primo-hermanito, es de aquí de San

21. La ausencia de esa figura pública como estrella se refleja sobre todo en las portadas de los primeros LP, donde no se destaca la personalidad de alguno de los músicos o la propia imagen del grupo; en su lugar, se presenta una imagen que remite a la playa y al mar. 
Nicolás" (Efrén Noyola, comunicación personal, 09.09.2016); “ese era de aquí de Corralero" (Cirino Arellano, comunicación personal, 08.07.2011), etc. El hecho de no hacer de ellos artistas, en un sentido mediatizado, le otorga a esta expresión un carácter eminentemente rural, que localmente se traduce en una cercanía con la audiencia que le acredita autenticidad. En ese sentido, conservan parte del perfil de relaciones sociales que se establecían antiguamente entre los músicos tradicionales y su comunidad de procedencia.

Por último, si bien los conjuntos tuvieron su auge entre los años setenta y los inicios del presente siglo, desde hace unos diez años, los llamados sonidos (disyoqueis que cuentan con equipo de amplificación de sonido y que manejan un amplio repertorio de grabaciones) comenzaron a desplazar el trabajo de los conjuntos en la región (Esteban Bernal, comunicación personal, 27.07.2018). La razón principal es el menor costo de contratación de sus servicios, comparado con el precio que cobran los grupos de música en vivo. Hasta hace un par de años, el sonido cobraba entre 10 ooo y 20 ooo pesos mexicanos por presentación, mientras que el grupo cobra alrededor de 50 ooo. El repertorio es otra razón que favorece la preferencia local de los sonidos por encima de los grupos de charanga, pues los primeros ofrecen un mayor número de géneros y piezas musicales para el baile. Paradójicamente, los sonideros, quienes hoy desplazan a los conjuntos, nutren su repertorio con la música compuesta por muchos de estos grupos de merequetengue e, incluso, incluyen piezas de danzas tradicionales que localmente son consideradas entrañables, como en el caso del son tradicional "Ya se van los diablos" de la danza Juego de diablos. Aunque el auge de los sonidos es ampliamente perceptible en la región, hoy por hoy, se considera que es un lujo contratar a un conjunto para acompañar el baile en alguna festividad comunitaria o privada.

\section{Hacia una dimensión musical translocal}

La Costa Chica ha sido una de las regiones económicamente más deprimidas de México. Si bien un alto índice de pobreza y marginación ha caracterizado a la región por décadas (Consejo Nacional de Evaluación de la Política de Desarrollo Social, 2019), durante los últimos tres decenios del siglo XX la situación económica empeoró, obligando a migrar a una gran cantidad de costeños hacia Acapulco, Oaxaca y la Ciudad de México, en busca de mayores oportunidades laborales. En la Ciudad de México, muchos de estos migrantes fueron insertándose en el tejido urbano mediante cadenas migratorias, fomentando el surgimiento de extensiones costeñas en la zona conurbada, como en los municipios de Los Reyes La Paz y Netzahualcóyotl, 
en el vecino Estado de México. La formación de núcleos poblacionales costeños en la gran ciudad creó un nuevo nicho cultural que propició la emergencia de un pequeño circuito de foros que con regularidad patrocinaban bailes de merequetengue, satisfactores de la demanda musical costeña. En el propio corazón de la Ciudad de México, diversos foros auspiciaron los bailes de charanga, como el salón California Dancing Club, un sitio legendario para los amantes del baile en una zona popular del sur de la ciudad.

Pero el destino migrante se reorientaría, desde los años ochenta, tomando un giro internacional hacia el llamado Norte (EE. UU.). La crisis económica nacional repercutió en algunas de las principales actividades económicas costeñas, como la agricultura, la ganadería y la pesca, lo cual detonó este cambio. En esa década, el principal punto de migración en Estados Unidos era el estado de California, y la mayoría de la población migrante comprendía jóvenes de entre 18 y 22 años que, terminando de cursar la escuela secundaria, optaban por migrar. El costo del viaje al Norte generalmente era financiado por la familia de la persona migrante, lo cual generaba un compromiso económico: una vez acomodados en trabajos medianamente estables en los Estados Unidos, la gran mayoría de los migrantes conservaban lazos con su familia, a quienes enviaban dinero con regularidad. Las remesas se convirtieron en recursos esenciales para la economía familiar de los que se quedaron en México, ayudando a la reactivación de algunas actividades económicas locales.

En un comienzo, la intención de una mayoría de los migrantes era migrar de manera temporal, con el propósito de ahorrar dinero y regresar a su región de procedencia para invertir en un negocio o construir una casa. En la costa abundan las historias sobre ese trasiego de ida y vuelta durante años. No obstante, a inicios de los años noventa, el cambio en las leyes migratorias y la creciente dificultad para cruzar la frontera modificó la situación general. En 1993, el estado de California endureció sus políticas inmigratorias; como resultado, el destino migrante de los costeños se redirigió a otros estados como Arizona y Texas, aunque fue en realidad Carolina del Norte el destino más favorecido.

En 1997, el paso del huracán Paulina por la Costa Chica acarreó tantas pérdidas en la región que la migración se tornó masiva a partir de ese año. Las cadenas migratorias no se hicieron esperar, algunas estimaciones locales señalaban que, para fines de los años noventa, uno de cada dos jóvenes costeños, entre los 18 y 30 años, se había aventurado en la experiencia migrante a EE. UU. (Benjamín Fuentes, comunicación personal, 23.01.2002). Antes de esta década, prácticamente no había mexicanos en Carolina del Norte, pero entre 1998 y 2010, esta entidad se convirtió en el estado con mayor número de migrantes latinos en EE. UU. (Lacy, 2009). La 
razón para migrar a un lugar tan lejano de la frontera con México era que encontraban en este estado menos violencia (drogas, pandillas), más tranquilidad (ausencia de sentimiento antiinmigrante), más trabajo, costos menores de manutención y una mejor calidad de vida (Jones, 2011); además de que por esos años las leyes de Carolina del Norte permitían un rápido acceso a las instituciones públicas: todavía en 2005 un inmigrante podía conseguir una licencia de conducir tan solo con aprobar el examen de manejo y contar con un par de direcciones locales y un número telefónico (Jones, 2011).

Alrededor de 1999, en Carolina del Norte los migrantes hombres solían ocuparse en trabajo manufacturero, empacado de carne, procesamiento de alimentos, plantación y cosecha de tabaco, durazno y tomate, así como en la industria de la construcción; mientras que las mujeres encontraban empleo generalmente en maquila, comercio y servicio doméstico (Lacy, 2009). En general, el patrón de migración interna de los costeños en EE. UU. continuó expandiéndose según la oferta de trabajo: actualmente se encuentran núcleos de costeños en California, Arizona, Texas, Pensilvania, Minnesota, Utah, Georgia, Carolina del Norte, Carolina del Sur, Chicago y Nueva York (Quecha, 2015). Si bien las condiciones de vida de muchos de estos migrantes mejoraron económicamente con respecto a sus opciones en México, su situación no se apartó de los patrones que han caracterizado a varias minorías racializadas residentes en EE. UU. (Sassen, 2019).

Las comunidades costeñas en los Estados Unidos conservan distintos tipos de lazos, algunos son cercanos y otros más individualistas. En algunos casos, han hecho redes locales de solidaridad y colaboración: en Pasadena, por ejemplo, crearon una pequeña isla costeña en medio de la megalópolis del sur de California desarrollando enclaves compuestos por tiendas, restaurantes, celebraciones a la virgen y el Día de Muertos (Lacy, 2009). Aunque una mayoría de costeños en EE. UU. se ha adaptado a algunas de las costumbres de este país, en general han tendido a mantener una fuerte identidad regional fuera de México. El precedente de una característica movilidad interna regional en la Costa Chica ha favorecido la convivencia entre costeños bajo el marco de una cultura compartida que los identifica, tomando como referente los vínculos simbólicos con su tierra.

Las fiestas son ocasiones de reafirmación identitaria y relación social donde rara vez falta la música grabada de merequetengue, pues representa un lazo emocional con sus comunidades de procedencia en México. Sin embargo, lo que tiene verdadero auge entre los costeños migrados son las presentaciones en vivo de estos grupos. El acordeonista Esteban Bernal destaca lo bien recibido que fue Mar Azul las veces que pudieron ir a presentarse a EE. UU., antes del endurecimiento de las 
leyes migratorias a inicios del presente siglo. En su momento, pudieron visitar ese país para ofrecer conciertos sin permisos de trabajo o contratos legales, aunque hoy esa opción ya no es viable ${ }^{22}$.

Sin embargo, uno de los grupos que pudo legalizar sus presentaciones en EE. UU. y que actualmente mantiene una relación intensa con las comunidades de migrantes costeños es El Original Mar Azul, que dirige Aquilino Hernández. Desde su resurgimiento, en 2016, esta agrupación ha logrado insertarse en un amplio circuito musical de clubes nocturnos que ofrecen presentaciones de grupos mexicanos en estados donde reside un número significativo de migrantes de la Costa Chica: California, Arizona, Utah, Alabama, Georgia, Carolina del Norte, Carolina del Sur, Indiana, Illinois, Minnesota, Wisconsin, Connecticut, Nueva York y Nueva Jersey (Figura 5). Como es de esperar, esos eventos suelen tener amplia concurrencia: en los últimos 3 años las giras de El Original Mar Azul por Estados Unidos han rebasado la treintena de presentaciones en un año.

Un aspecto interesante sobre la perduración de este grupo en el gusto costeño transnacional es que su continuidad no implicó la emergencia de un nuevo estilo musical o cambios significativos en las presentaciones, como en el caso de otras expresiones musicales en contextos migrantes (García; Luengas, 2016; Olmos, 2012; Simonett, 200o). Por el contrario, se puede decir que parte significativa del éxito actual de Mar Azul entre la población migrante en EE. UU. se debe a que su música, estando en pleno auge en la Costa Chica durante el período álgido de migración (1980-200o), favoreció que estos repertorios se fijaran en la experiencia migrante que hoy se constituye en una audiencia multilocalizada. El vínculo identitario que esta música ejerce en esas primeras generaciones de migrantes ha llevado a El Original Mar Azul a conservar los viejos repertorios y eludir demasiados cambios en las nuevas composiciones, apegándose a reproducir el sonido merequetengue de los años ochenta.

Además, si bien los lugares de presentación han transitado de los espacios públicos colectivos de las comunidades a los salones de baile urbanos, la importancia del baile para la audiencia ha mantenido a este grupo distante de los auditorios de conciertos; el uso de modestos sistemas de luces y sonido, así como la ausencia de juegos pirotécnicos y macropantallas en el escenario caracterizan todavía sus presentaciones. Tampoco forman parte de las redes mediáticas masivas, con excepción de la promoción de sus presentaciones en estaciones de radio. De alguna forma, esta 
FIGURA $5 \quad$ Cartel de baile en Nueva Jersey (EE. UU.)

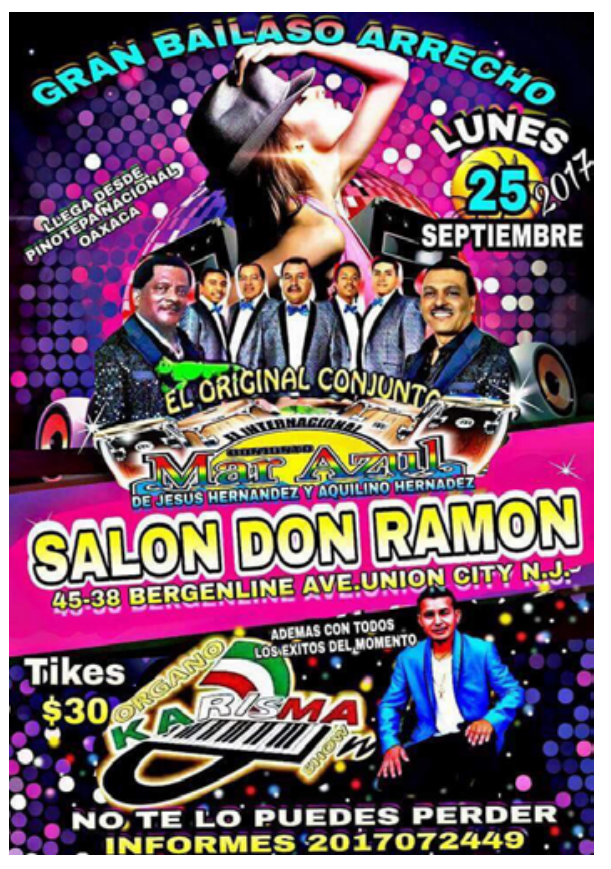

Fuente: página oficial de Facebook de Don Ramon Nightclub. https://es-la.facebook.com/donramonnightclub/photos/a.235 $877776559676 / 873854776095303 /$ type $=3 \&$ theater

agrupación continúa funcionando de manera independiente de la gran industria musical, tanto en su región de origen como en Estados Unidos.

La música de Mar Azul representa un símbolo de identidad que alude a un "regionalismo nostálgico" (Hutchinson, 2006: 66) en la experiencia migrante; por medio de esta música se articula la memoria de su tierra, localizándolos en un nuevo lugar, pero sin dejar por completo su identidad regional. Asimismo, su carácter transnacional intensifica los lazos de identificación regional en la diáspora, marcando delimitaciones en términos de especificidad geográfica. Mediante esta música, los migrantes encuentran un sentido de pertenencia a su sitio de procedencia, pues los identifica como mexicanos, pero a la vez les distingue como costeños entre la población mexicana en EE. UU. Para los migrantes costeños, principalmente los de primera generación, el gusto por esta música establece claras fronteras de pertenencia que remiten a su región de origen.

Así, el consumo de merequetengue demarca y reafirma una localidad regional, tanto en México -donde históricamente se ha ignorado a la Costa Chica-como en 
el vecino país del norte -donde duplica su importancia en condiciones de minoría étnica para los costeños migrantes-. La experiencia migrante ha cruzado por completo la vida de los costeños residentes en los Estados Unidos, quizá por ello, una de las piezas más populares entre la audiencia consumidora de esta música sea "Me voy pa' Carolina", del acordeonista Esteban Bernal, quien en sus letras hace eco de esta vivencia para una diversidad de personas, no solo de la Costa Chica, sino de todo México, que han buscado mejores oportunidades laborales en los EE. UU.:

Ya me voy pa Carolina

y no voy arrepentido

porque todas las mujeres

no quieren estar conmigo.

Melitón Cisneros dijo:

"Oyes, Esteban Bernal, dicen que tú ya no puedes

y por eso ya te vas..."

Yo le digo a Melitón:

"Yo soy Esteban Bernal, vamos a tomar botellas

y verás que asi no se van...”23

El éxito de esta pieza propició que, unos años después, el propio Esteban Bernal compusiera otra llamada "Ya me vine de Carolina":

Ya llegué, ya estoy aquí, ya me vine de Carolina; ya no quiero estar allá, me desprecian esas gringas.

Yo me acuerdo de mi tierra, quiero ver a mi negrita, porque siento que no aguanto, quiero besar su boquita. 
Las redes sociales, en internet, han tomado un lugar relevante como espacios activos de socialización, al mantener en contacto a las comunidades migrantes. Los bailes siguen siendo importantes referentes identitarios que son registrados audiovisualmente por una diversidad de actores, tanto en México como en EE. UU. Los residentes locales, con sus propias habilidades y competencias culturales, registran y socializan de manera expedita fragmentos significativos de los bailes con amigos y parientes migrantes. Asimismo, se exponen en las redes una gran cantidad de materiales audiovisuales con la música de Mar Azul o alguna de sus presentaciones en vivo; al estar expuestos de manera global, son consumidos por costeños dispersos en una diversidad de países que revaloran la cultura local. Parte significativa de los comentarios en las redes sociales versa en torno a la originalidad y calidad de cada una de las facciones de Mar Azul; la mayor cantidad de este material ofrece la oportunidad de observar perspectivas y valores locales, a veces como comentarios individuales y, en otras ocasiones, como diatribas entre distintos comentaristas.

En el caso costeño, al menos hasta el cambio de siglo, la red de relaciones sociales se circunscribía al lugar y su proximidad física y cultural, pero luego del período de intensa migración, el lugar pasó a ser una metáfora en la construcción simbólica como forma cultural desterritorializada de tinte translocal. Delineando este tránsito de expresiones locales a translocales, los migrantes de la Costa Chica han utilizado la música de su terruño para apropiarse de espacios distantes, cultural y geográficamente, de sus lugares de origen. La música funge entonces como un medio por el cual la situación de lugar es negociada y transformada, construyendo trayectorias de su tierra a través del espacio (Stokes, 1997); proceso ampliamente perceptible tanto en Ciudad de México como en las distintas entidades receptoras de migrantes costeños en Estados Unidos.

\section{Conclusiones}

En el presente escrito, se ha visto cómo un género procedente del hemisferio sur impactó regiones rurales distantes ubicadas en países periféricos del mismo Sur Global. El trasiego del sonido corralero colombiano tuvo rápida aceptación en la Costa Chica de México, siendo adaptado al gusto regional mediante la producción musical original de agrupaciones locales emergentes como Mar Azul.

Este y otros grupos surgieron en condiciones históricas específicas caracterizadas por una mayor comunicación de la Costa Chica con el exterior, el declive de ciertas expresiones festivas tradicionales, así como la popularización de aparatos reproductores de fonogramas, aunados al auge de la música tropical a nivel nacional 
e internacional. Mientras que artistas como Rigo Tovar (y su conjunto Costa Azul) o Acapulco Tropical acaparaban el mercado urbano de la clase trabajadora inmigrante a las grandes ciudades, grupos como Mar Azul fraguaban una música de carácter local/regional que aprovechaba este boom tropical de los años setenta.

La música del patio colombiano fue motivo creativo para la sensibilidad costeña. En la producción musical de Mar Azul, elementos como la lírica de las canciones, los ensambles instrumentales y el estilo musical fungieron como vehículos de una estética particular que, en conjunción con la noción de lugar y los vínculos comunitarios, construyeron una vigente localidad regional. En pocos años, los bailes de charanga se convirtieron en sitios de reconocimiento y pertenencia a un espacio local circunscrito a una historia y cultura compartidas. El éxito de Mar Azul, y del merequetengue en general, adquirió tal importancia, que conformó no solo circuitos de circulación y consumo en el nivel regional, sino que estos trascendieron a los principales destinos de migración costeña. La consolidación de una estética compartida a nivel regional favoreció el consumo translocal de esta música en la Ciudad de México, así como en una imaginada comunidad costeña allende las fronteras mexicanas.

Los migrantes de la Costa Chica en EE. UU. han tendido a mantener una identidad regional fuera de su lugar de origen; en dicha construcción identitaria, el papel de la música de merequetengue ha jugado un papel primordial. Si bien el merequetengue de Mar Azul no fue una expresión difundida masivamente por la industria musical, sino una música popular de carácter rural surgida en un momento previo al auge de la llamada world music, el propio éxito transnacional de los grupos tropicales de los años setenta impulsó a estos grupos a encontrar sus propios derroteros entre las comunidades costeñas radicadas en Estados Unidos. Parte fundamental de la permanente vigencia de los repertorios de Mar Azul correspondientes a los años setenta, ochenta y noventa, tiene que ver con la gran significación que tuvieron para toda una generación de costeños y su experiencia migrante. Ello explica por qué los repertorios han tendido a conservarse hasta hoy sin demasiados cambios.

Actualmente, el merequetengue sigue presente en el gusto musical costeño, aunque con menor fuerza que antaño, luego del surgimiento y permanencia de los sonidos; no obstante, en el universo musical costeño continúa teniendo un importante papel social, siempre entreverado con el consumo de música tradicional regional (sones, corridos y chilenas) y de música popular con presencia a nivel nacional (banda norteña, música ranchera, balada romántica y reguetón). Para el caso de los migrantes costeños radicados en la Ciudad de México y EE. UU., el merequetengue prevalece con fuerte vigencia al ayudar a construir una identidad regional costeña que les distingue no solo en contextos extranjeros, sino incluso ante sus connacionales dentro y fuera de México. 
En suma, el presente escrito muestra un caso más que ilustra la diversa gama de procesos musicales globales ocurridos desde fines del siglo pasado en Latinoamérica. En específico, se da cuenta aquí de las condiciones dinámicas en las que se ha desarrollado parte de la cultura musical costeña durante las últimas décadas; procesos donde puede observarse la manera en que aflora la "culturalidad de la vida humana" (Robertson, 1992: 173).

\section{Referencias}

Alvarado, Nadia (2012). Desde la Costa de Guerrero hasta Chacahua, tras la pesca del tiburón, nació El Mar Azul: José Antonio Tornez. Pinodebate. Recuperado de https://pinodebate. blogspot.com/2012/11/desde-la-costa-de-guerrero-hasta.html

Bennett, Andy (2015). The Global and the Local. En The SAGE Handbook of Popular Music (pp. 223-225), editado por Andy Bennett; Steve Waksman. London: SAGE Publications.

Bennett, Andy; Peterson, Richard (eds.), (2004). Music Scenes: Local, Trans-local and Virtual. Nashville, TN: Vanderbilt University Press.

Blanco, Darío (2003). La relación música e identidad. El movimiento regio-colombiano, sincretismo en México de la música de la costa atlántica colombiana. [Tesis de maestría]. Universidad Autónoma Metropolitana-Iztapalapa, Postgrado en Ciencias Antropológicas, Ciudad de México.

Blanco, Darío (2005). Transculturalidad y procesos identificatorios. La música caribeña colombiana en Monterrey. Alteridades, 15(30), 19-41.

Blanco, Darío (2008). La cumbia como matriz sonora de Latinoamérica. Los colombias de Monterrey-México (1960-20o8). Interculturalidad, identidad, espacio y cuerpo. [Tesis de doctorado]. El Colegio de México, Centro de Estudios Sociológicos, Doctorado en Ciencia Social, Ciudad de México.

Burgos, Alberto (2001). Antioquia bailaba así. Medellín: Lealón.

Consejo Nacional de Evaluación de la Política de Desarrollo Social (2020). Medición de la pobreza. Recuperado de https://www.coneval.org.mx/Medicion/Paginas/PobrezaInicio.aspx

Espectacular bailazo de feria en Bajos de Coyula (2019). Todo Huatulco. Recuperado de https:// todohuatulco.com/2019/11/10/espectacular-bailazo-de-feria-en-bajos-de-coyula/

García, Patricia; Luengas, Rubén (2016). Mixtechno. Las nuevas tecnologías en las antiguas músicas mixtecas. En Música indígena y contemporaneidad: nuevas facetas de la música en las sociedades tradicionales (pp.49-69), coordinado por Miguel Olmos. Tijuana: El Colegio de la Frontera Norte. 
Geijerstam, Claes af (1976). Popular Music in Mexico. Albuquerque: University of New Mexico Press.

Haque, Habibul (2019). Glocalization. En The Oxford Handbook of Global Studies (pp. 93-112), editado por Mark Juergensmeyer; Saskia Sassen; Manfred B. Steger. New York: Oxford University Press.

Hernández, Oscar (2015). Los mitos de la música nacional:podery emoción en las músicaspopulares colombianas. La Habana: Casa de las Américas.

Hutchinson, Sydney (2006). Merengue Típico in Santiago and New York. Transnational Regionalism. Ethnomusicology, 5o(1), 37-72.

Hutchinson, Sydney (2016). Merengue on the Move. Making Music, Place, and Community in the Típico World. En Made in Latin America (pp. 113-124), editado por Julio Mendívil; Christian Spencer. New York/London: Routledge.

Instituto Nacional de Estadística y Geografía (2001). Indicadores Sociodemográficos de México (1930-2000). México: INEGI.

Jones, Jennifer A. M. (2011). Making Race in the New South: Mexican Migration and Race Relations in Winston-Salem, North Carolina [Tesis de doctorado]. University of California, Graduate Division in Sociology, Berkeley.

Lacy, Elaine (2009). Cultural Enclaves and Transnational Ties: Mexican Immigration and Settlement in South Carolina. En Latino Immigrants and the Transformation of the U.S. South (pp. 1-17), editado por Mary Odem; Elaine Lacy. Athens/London: University of Georgia Press.

Méndez, Mario (2016). Regresa al ruedo el original Mar Azul con "La Historia continua". NSS Oaxaca. Recuperado de https://www.nssoaxaca.com/2016/o3/28/regresa-al-ruedo-eloriginal-mar-azul-con-lla-historia-continuar/

Middleton, Richard; Manuel, Peter (2001). Popular Music. En The New Grove Dictionary of Music and Musicians, editado por Stanley Sadie. London: Oxford University Press. Recuperado de https://www.oxfordmusiconline.com/grovemusic/view/10.1093/ gmo/9781561592630.001.00o1/omo-9781561592630-e-ooooo43179

Montoya, Luis Omar (2014).El síndrome de la nostalgia. Guanajuato:Universidad de Guanajuato/ INAH.

Moreno, Yolanda (1989). Historia de la Música Popular Mexicana. México: Alianza Editorial Conaculta.

Olmos, Miguel (coor.), (2012). Músicas migrantes. La movilidad artística en la era global. Tijuana: El Colegio de la Frontera Norte/Universidad Autónoma de Sinaloa/Universidad Autónoma de Nuevo León. 
Olvera, José Juan (2000). Alnorte del corazón. Evoluciones e hibridaciones musicales en el noreste mexicano y sureste de los Estados Unidos con sabor a cumbia. Ponencia presentada en el III Congreso Latinoamericano de la Asociación Internacional para el Estudio de la Música Popular, Bogotá. Recuperado de http://iaspmal.com/index.php/2016/o3/o2/actas-iiicongreso-bogota-colombia-20oo/?lang=pt

Olvera, José Juan (2005). Colombianos de Monterrey. Origen de un gusto musicaly su papel en la construcción de una identidad. Monterrey: Consejo para la Cultura de Nuevo León.

Parra, Juan Diego (2017). Deconstruyendo el chucu-chucu. Auges, declives y resurrecciones de la música tropical colombiana. Medellín: ITM.

Parra, Juan Diego (comp.), (2019). El libro de la cumbia. Resonancias, transferenciasy transplantes de las cumbias latinoamericanas. Medellín: ITM/Discos Fuentes Edimusica.

Quecha, Citlali (2015). Niñas cuidadoras en contextos migratorios. El caso de las poblaciones afrodescendientes en la Costa Chica de Oaxaca. Cuicuilco, 64, 155-173.

Robertson, Roland (1992). Globalization. Social Theory and Global Culture. Thousand Oaks, CA: SAGE Publications.

Robertson, Roland (1995). Glocalization. En Global Modernities (pp. 25-44). London: SAGE Publications.

Ruiz, Carlos (2013). Del fandango al baile de artesa. Declive, resurgimiento y sobrevivencia de una tradición musical de la Costa Chica. En El Fandangoy sus variantes. III Coloquio Música de Guerrero (pp. 249-266), editado por Amparo Sevilla. México: INAH.

Sassen, Saskia (2019). Researching the Localizations of the Global. En The Oxford Handbook of Global Studies (pp. 73-92), editado por Mark Juergensmeyer; Saskia Sassen; Manfred B. Steger. New York: Oxford University Press.

Simonett, Helena (2000). Popular Music and the Politics of Identity. The Empowering Sound of Technobanda. Popular Music and Society, 24(2), 1-23.

Stokes, Martin (1997). Ethnicity, Identity and Music. The Musical Construction of Place. Oxford/ New York: Berg Publishers.

Straw, Will (1991). Systems of Articulation, Logics of Change: Communities and Scenes in Popular Music. Cultural Studies, 5(3), 368-388.

Wong, Ketty (2012). Whose National Music? Identity, Mestizaje, and Migration in Ecuador. Philadelphia: Temple University Press. 